\title{
Injuries associated with bunk beds that occur in jail
}

\author{
Randall T. Loder, MD* \\ Jocelyn Cole Young, BA, BS^ \\ Department of Orthopaedic Surgery, Indiana University School of Medicine and James Whitcomb Riley \\ Children's Hospital, Indianapolis, Indiana, 46202 USA \\ $\wedge$ School of Medicine, Indiana University, Indianapolis, Indiana \\ This research was supported in part by the Garceau Professorship Endowment, Indiana University, School \\ of Medicine, Department of Orthopaedic Surgery, and the Rapp Pediatric Orthopaedic Research \\ Endowment, Riley Children's Foundation, Indianapolis, Indiana.
}

This is the author's manuscript of the article published in final edited form as:

Loder, R. T., \& Young, J. C. (2017). Injuries associated with bunk beds that occur in jail. Journal of Forensic and Legal Medicine. https://doi.org/10.1016/j.jllm.2017.10.007 
Injuries associated with bunk beds that occur in jail 


\begin{abstract}
Background: There are many studies of bunk bed injuries, but none specifically addressing those occurring in jails. It was the purpose of this study to investigate the magnitude and patterns of bunk bed injuries occurring in correctional institutions.
\end{abstract}

Methods: The National Electronic Injury Surveillance System (NEISS) data for the 10 year period 2006 through 2015 due to bunk beds was accessed. Injuries involving bunk beds were identified and the mechanism of injury determined. Statistical analyses were performed with SUDAAN $10^{\mathrm{TM}}$ software. A $\mathrm{p}<0.05$ was considered statistically significant.

Results: There were an estimated 639,505 ED visits for bunk bed associated injuries; 51,204 occurred in jail. All jail cases occurred in the age groups $\geq 10$ years $(177,165)$; $29 \%$ of these 177,165 sustained the injury in jail. Those who sustained a bunk bed injury in jail compared to those who did not were older, more commonly male, seen in smaller hospitals, more likely admitted, and more frequently associated with a seizure. For those injuries occurring in jail, the most common injury in the trunk and lower extremity was a strain/sprain; the upper extremity a contusion/abrasion; and the head/neck a laceration or traumatic brain injury. A fall off the bunk bed accounted for $71.8 \%$ of the injuries, had the highest hospital admission rate (7.4\%), accounted for all of the spine injuries, $96 \%$ of the head injuries, and had the highest proportion of fractures $(14.4 \%)$. Inmates having a seizure before the injury sustained fewer fractures, more lacerations, and more head/neck injuries.

Conclusions: Injuries in jail account for $29 \%$ of all bunk bed injuries resulting in an ED visit in the USA in those age groups $\geq 10$ years. A fall from the bed occurred in $72 \%$ and a seizure disorder was 4.5 times more common in jail inmates compared to non inmates. Possible prevention strategies include railings/ladders to reduce the incidence of falls, changes in flooring surfaces, and seizure education and placing inmates with seizure and/or alcohol related disorders on the bottom bunk. This will require a multidisciplinary approach involving the disciplines of medicine, material engineering, and criminal justice.

Key Words: bunk bed - injury - jail - seizure - fall 


\section{Background and rationale for the study}

Physicians are often called upon to care for patients, especially children, who have sustained injuries falling from a bunk bed. Of the bunk bed injury studies ${ }^{1-7}$, none specifically investigate those occurring in different housing locations. In an ongoing study of injuries associated with bunk beds, it was anecdotally noted that a bunk bed injury while the patient was in jail was common. To our knowledge there is no study specifically addressing bunk bed injuries which occur in correctional institutions. We thus wished to investigate the magnitude and patterns of bunk bed injuries occurring in correctional institutions. As this was an exploratory study, there were no null hypotheses, but rather a descriptive study that might guide further investigation and injury prevention avenues.

\section{Materials and methods}

\subsection{Data source}

The data in this study comes from the National Electronic Injury Surveillance System (NEISS). The NEISS is a dataset maintained by the US Consumer Product Safety Commission, which collects injury data from $\sim 100$ hospitals in the United States and its territories. Patient information is collected from each NEISS hospital for every emergency department (ED) visit involving an injury associated with consumer products. This data base is in the public domain and can be found at www.cpsc.gov/library/neiss.html. Details regarding the acquisition of the NEISS data and guidelines for its use can be accessed from the above web site. This study was classified as exempt by our local Institutional Review Board.

The NEISS data base includes stratified hospital size, date of ED visit, product involved in the injury, gender/race/age of the injured patient, diagnosis, disposition from the ED, geographic location of the injury, and body part injured. At the end of every case are narrative comments giving further details. The hospital strata are comprised of 4 hospitals based on size (the total number of ED visits reported by the hospital which are small [0-16,830], medium [16,831-21,850], large [28,151-41,130], and very large $[>41,130])$ and 1 stratum consisting of children's hospitals of all sizes. From this stratified and weighted sample, an estimated total number of product related injuries treated in hospital EDs is calculated.

\subsection{Collected data}

The data for the 10 year period 2006 through 2015 due to bunk beds (NEISS product code 0661) was downloaded from the NEISS website into a Microsoft Excel'TM file (Microsoft ${ }^{\mathrm{T}}$ Office 2003, Microsoft Corporation 1985-2003). Race was classified according to Eveleth and Tanner ${ }^{8}$ as White, Black, Amerindian (Hispanic and Native American), Indo-Malay (Asian origins), Indo-Mediterranean (Middle Eastern and Indian subcontinent), and Polynesian. Due to the small numbers of Indo-Malays, 
Indo-Mediterranean, and Polynesian peoples in the data set, race/ethnicity is only reported for the White, Black, and Amerindian groups.

Injuries occurring in jails were identified by searching the narrative comments for each case using the FIND command in Excel ${ }^{\mathrm{TM}}$. This search was performed solely by one author to ensure consistency in identification. The terms used in the search were jail, prison, incarcerate(d), detention, correctional institution, prisoner, inmate, custody, police, law enforcement, justice, center. Only when the narrative comments were appropriately detailed to ensure that the patient was truly in a jail was the case marked as such. Throughout the remainder of this manuscript, the term jail will be used for all correctional institutions.

The mechanism of injury was obtained from the individual narrative comments. Five major mechanisms were identified: 1) falling out of the bunk bed, 2) jumping in some manner on the bunk bed, 3) striking/hitting the bunking bed, 4) getting onto the bunk bed, or 5) getting off the bunk bed. The injured anatomic areas are reported three ways. The first is a detailed breakdown (Table 1), which was then condensed into two different classifications. The first classification collapsed the upper extremity injuries into one group and the lower extremity injuries into another group. The second classification placed neck injuries into the axial group, and collapsed upper and lower extremity injuries into an appendicular group. While reviewing the narrative comments it was often noted that the patient had a seizure and then sustained an injury. Thus the FIND command was used to search for the terms seizure, seizing, seized, and epilepsy to identify those who had a seizure before the incident.

Subcategories were created for further analyses and were: age groups, those with/without a fracture, a head injury, and an internal organ injury. A fracture was defined as an osseous fracture, excluding teeth and other organs. Narrative comments were reviewed to find fractures which were not coded as the primary diagnosis when a more severe injury was actually the primary diagnosis. In a few cases, an injury coded as a fracture was a "fracture" of an organ such as the spleen or eye, and were deleted as a fracture. A head injury was defined as a concussion, skull fracture, or any bleed within the calvarium. A traumatic brain injury (TBI) in this study excluded a skull fracture, while the head injury category included a skull fracture. Internal organ injuries were defined as any injury involving the lung, heart, mediastinum, trachea/larynx, abdominal organs [liver, spleen, kidney, pancreas, intestines, genitourinary organs $\{$ bladder, testicle, scrotum, vagina, uterus $\}$, and head injury excluding skull fracture. Due to this refinement of data using the narrative comments, the estimated numbers given in the tables are not totally identical when comparing the head injury and traumatic brain injury groups, and the fracture yes/no groups with a fracture as the diagnosis in the major diagnosis categories.

\subsection{Statistical analysis}


Statistical analyses were performed with SUDAAN $10^{\mathrm{TM}}$ software (RTI International, Research Triangle Park, North Carolina, 2008) due to the stratified and weighted nature of the NEISS data to account for the weighted and stratified nature of the data. Such analysis calculates an estimated value across an entire population encompassed by the data set along with $\pm 95 \%$ confidence intervals [CI]. For the purposes of reporting our results, we include the raw number of patients (n), the estimated number (est), and 95\% CI [lower, upper]. Analyses between groups of continuous data were performed with the Student's t-test (2 groups) or ANOVA ( 3 or more groups). Differences between groups of discrete data were analyzed by the $\chi^{2}$ test. A $\mathrm{p}<0.05$ was considered statistically significant.

\section{Results}

There were 20,742 ED actual visits for bunk bed associated injuries resulting in an estimated $639,670[542,965,736,045]$ visits. All of those occurring in jail were in the 10 to 14 year age group or beyond. We therefore excluded those in the 0 to 4 and 5 to 9 year age groups, and are reporting only on the subset of patients over 10 years of age $(n=4,976$, est $=177,165[144,213,210,117])$. Of these 177,165 cases, $51,204[35,082,55,860](n=1,381)$ occurred in jail $(28.9 \%)$. We analyzed the data set to ensure that we identified all injuries which occurred in jail. All the 1,381 injuries that we identified as occurring in jail, using the FIND command, had the NEISS location code of 5, which is other public property. We thus feel confident that the data is accurate. In the following sections we report results with notable differences. All results (notable or not) for all variables, with their n, est, 95\% CIs, and p values, are given in the supplemental tables.

\subsection{Comparison between those in or out of jail}

Analyses between those occurring in or out of a jail demonstrated no differences by year, month, or weekday of injury, and so no further temporal analyses are reported. Those who sustained a bunk bed injury in jail compared to those who did not (Supplemental table 1) were older $(33.5$ [32.2, 34.8] vs 24.2 $[23.2,25.2]$ years $(\mathrm{p}<0.001)$, more commonly male $(81.2 \%$ vs $53.8 \%$, p < 0.0001$)$, seen in smaller hospitals $(50.2 \%$ vs $27.8 \%, \mathrm{p}<0.001)$, more likely admitted $(6.4 \%$ vs $3.2 \%, \mathrm{p}=0.0051)$, more frequently associated with a seizure (3.6\% vs $0.8 \%)$, and less frequently associated with alcohol use $(0.2 \%$ vs $1.7 \%$, $\mathrm{p}=0.003)$. The injuries more frequently involved the trunk (21.9\% vs $16.2 \%)$ and less frequently the lower extremity $(16.2 \%$ vs $24.3 \%)(\mathrm{p}<0.0001)$. There were no differences by race, major diagnosis, or presence/absence of a head injury or a fracture.

\subsection{Injury patterns for those in jail}

The anatomic area injured (Supplemental table 2) was the trunk in $22.1 \%$, upper extremity in $20.6 \%$, lower extremity in $16.4 \%$, and head/neck in $40.9 \%$. Those having a head/neck or trunk injury were more commonly admitted $(9.7 \%$ and $6.6 \%)$ compared to the upper or lower extremity $(0.5 \%$ and $4.3 \%)(\mathrm{p}=0.0033)$. The most frequent diagnosis for the trunk and lower extremity was a strain/sprain 
(51.4\% and $43.5 \%)$, upper extremity a contusion/abrasion (45.2\%), and head/neck a laceration or traumatic brain injury $(35.7 \%$ and $25.2 \%)(\mathrm{p}=0.001)$. Fractures were most frequent in lower extremity injuries (18.9\%) and least common in head/neck injuries (6.5\%). Although the most common mechanism of injury was falling off the bed (71.8\%), jumping on the bed accounted for a higher percentage of lower extremity injuries (29.6\%) compared to the other body sites where jumping on the bed ranged from $2.9 \%$ to $5.4 \%,(\mathrm{p}=0.0012)$.

The major diagnoses (Supplemental table 3) were a strain/sprain in 30.2\%, contusion/abrasion in $27.6 \%$, a laceration in $19.3 \%$, a fracture in $12.6 \%$, and a TBI in $10.4 \%$. Lacerations were extremely rare in women with only $4.5 \%$ of the lacerations occurring in females compared to the overall female percentage of $18.8 \%(\mathrm{p}=0.0066)$. Those with fractures were the oldest $(37.3$ years $[34.9,39.8])$ and lacerations the youngest $(30.8$ years $[28.2,33.5])(\mathrm{p}<0.0001)$. Hospital admission was more common in patients with fractures (20.7\%) and TBIs (20.2\%) compared to contusion/abrasions (1.6\%), lacerations $(2.6 \%)$, and strain/sprains $(2.7 \%)(\mathrm{p}=0.0003)$. Lacerations were more common in those who hit the bed (29.9\%) compared to the other mechanisms where lacerations ranged from $1.0 \%$ to $9.5 \%$ of the injuries.

The narrative comments were adequate to determine the mechanism of injury for 50,252 [34,535, $65,965]$ cases (Supplemental table 4). The most frequent mechanism was falling off the bed $(71.8 \%)$, followed by hitting the bed (10.8\%), jumping on the bed (8.5\%), getting off the bed (5.0\%) and getting into the bed (4.0\%). Hospital admission was the highest for those who fell off the bed (7.4\%) and the lowest for those who were getting into the bed $(0.9 \%)(\mathrm{p}=0.009)$. A fracture occurred in $14.4 \%$ of those who fell from the bed and $11.9 \%$ of those who were jumping on the bed, compared to $1.1 \%$ of those who hit the bed $(\mathrm{p}=0.0003)$. Seizures were only seen in those who either hit the bed $(5.3 \%)$ or fell off the bed $(4.4 \%)(\mathrm{p}=0.004)$.

Seizures occurred in $3.6 \%$ of the patients (Supplemental table 5). A fracture occurred in $0.9 \%$ of those with a seizure and $12.7 \%$ without a seizure $(p=0.005)$. A laceration occurred in $30.6 \%$ of those with a seizure and $18.9 \%$ without, and a TBI in $21.6 \%$ of those with and $19.9 \%$ of those without a seizure $(\mathrm{p}=0.0054)$.

The size of the hospital where the patient was evaluated (Supplemental table 6) was small in $50.2 \%$, very large in $21.3 \%$, large in $15.3 \%$, and medium in $13.1 \%$. We deleted from analysis the very small number of cases seen at children's hospitals. A head injury occurred in $7.1 \%$ of those seen at small hospitals and $15.5 \%$ of those at very large hospitals $(p=0.009)$. The larger hospitals are likely in major urban areas, reflecting inner city jails, while the small hospitals in smaller cities, reflecting county jails.

\section{Discussion}

Bunk beds allow for two or more people to sleep in the same vertical space maximizing available living area. Bunk beds are thus commonly used in cramped living situations, such as dormitories, 
military barracks, camp cabins, hostels, and jails, but such bed positioning increases the potential for injury. The majority of injuries from bunk beds occur in children as has been noted in many studies $1-7$ as well in this study, where $72.3 \%$ occurred in those under 10 years of age. There is little information regarding bunk bed injures in adults, and there are no studies of bunk bed injuries in jail inmates.

There are certain limitations to this study. First, the NEISS only identifies individuals who sought care in an ED. Second, identification of the jail associated injuries relied on the narrative comments in the NEISS data. If no jail was mentioned yet was involved in the injury, that case would not have been identified. Thus the overall number of injuries in this study is likely lower than the true number; the magnitude of this difference is impossible to determine. Another potential limitation is the accuracy of the NEISS data. However two studies have demonstrated over $90 \%$ accuracy 9,10 .

\subsection{Injury in jail}

With these caveats in mind, this is the first study to specifically investigate injuries associated with bunk beds in jails. In this study, an estimated $28.9 \%$ of bunk bed injuries necessitating an ED visit in those 10 years or older occurred in jails, for an annual average of 5,120 ED visits. The actual number of injuries associated with bunk beds occurring in jails is likely higher, as this study only identifies those who were actually taken to the ED by jail personnel. In one jail system there were 11 bunk bed accidents in 85,408 inmates from 1999 to $2003^{11}$. It was also estimated that in a jail of 1,750 inmates, the number of times an inmate climbed onto the upper bunks in one year was $1,277,500{ }^{11}$. Thus the number of bunk bed injuries relative to the number of times inmates climbing in and out of bunk beds is quite small. Further research is needed regarding the actual prevalence of bunk bed injuries in jail inmates. The $6.4 \%$ admission rate for the jail bunk bed related injuries is double the $3.2 \%$ occurring out of jail. If hospital admission is used as a proxy for injury severity, then bunk bed injuries occurring in jail are more severe than those occurring outside of jail.

Injury in jail inmates is increasingly important as the medical issues of HIV and tuberculosis in jails is decreasing $12-14$. Although we do not know the time an inmate has been incarcerated in this study as it is not part of the NEISS data, the likelihood of an injury in a jailed person increases with increasing incarceration time ${ }^{15}$. An inmate incarcerated for 1 year or more had a $17.0 \%$ chance of an accidental injury and a $15.9 \%$ chance of injury from a fight. In the 2002 Survey of Inmates in Local Jails ${ }^{12}$, a self reporting study of 6,982 inmates weighted to the entire USA jail population, the accident related injury rate per 100,000 inmates was just slightly lower than that for the entire USA population (7,276.9 vs. 9,381.8).

\subsection{Seizures}


Although the overall prevalence seizures was low, it was 4.5 times higher in the jail group (3.6 vs. $0.8 \%$ ) in this study. This is similar to other studies. Durand et al ${ }^{16}$ noted a $5.9 \%$ prevalence of epilepsy in a French prison population. Novick ${ }^{17}$ noted a prevalence of seizures in recently admitted New York City prison inmates of $3.6 \%$ in males and $7.5 \%$ in females. King et. al. ${ }^{18}$ noted the prevalence of seizures was three times higher in a prison population than in the adult non-prisoner population adjusted for age. The prevalence of seizures in 1,200 pretrial detainees entering the Cook County, Illinois Department of Corrections was $6 \%$. Seizures occurring in prison inmates is particularly concerning, as 10 of $53(\sim 20 \%)$ deaths in prisoners were associated with seizures in one study ${ }^{19}$. Two recent studies of medical problems in jail inmates 14,15 did not specifically mention seizures. This topic needs further investigation.

\subsection{Prevention strategies}

Most of the injuries occurred during a fall from the bunk bed (71.8\%). Prevention strategies should therefore be directed at such falls. One possibility is to have ladders and railings in the hope that they would reduce the number of falls from the upper bunks. The narrative comments in the NEISS data base do not give enough detail to know if there were ladders to aid in climbing into the upper bunk or railings to prevent someone from falling out of the upper bunk. There are bunk bed safety standards for individual formulated by the Consumer Product Safety Commission which are outlined in the Code of Federal Regulations, sections 1513 and $1213^{20}$ (https://www.gpo.gov/fdsys/pkg/cfr-2017-title 16vol2/pdf/CFR-2017-title16-vol2.pdf). These standards prescribe requirements for bunk beds to reduce or eliminate the risk that children will die or be injured from being trapped between the upper bunk and the wall, in openings below guardrails, or in other structures in the bed. They also prohibit manufacture for sale, offer for sale, distribute in commerce or import into the United States a bunk bed subject to the standard that does not meet the standard's requirement. However, the Code of Federal Regulations clearly states that these recommendations do not apply to bunk beds manufactured only for industrial use. This immunity from the Code of Federal Regulations requirements for prisons has been upheld by the US Federal Courts 11 .

Having ladders or railings as a prevention mechanism in jails risks the safety and security of correctional officers. Thus any decision to equip bunk beds with ladders and railings is a balance between the safety of prisoners and correctional officers ${ }^{11}$, as noted in the above legal decision which stated "Such a decision is characterized by a high degree of discretion and the weighing of the alternatives, and therefore, warrants immunity." In a study of injuries to correctional officers ${ }^{21}$, non fatal occupational 
injuries occurred in 3 per 100 FTEs. Of the injuries, $38 \%$ were assaults and violent acts; $96 \%$ were treated and released from the ED. The issue of bunk bed ladders or railings in that study ${ }^{21}$ was not discussed.

Another prevention strategy would be to ensure that inmates with a known seizure disorder sleep on the bottom bunk. The possibility of newly admitted inmates having alcohol related problems and the potential for withdrawal seizures should be remembered, as such seizures typically occur within the first

48 hours after alcohol abstinence ${ }^{22}$. There is inadequate assessment of alcohol withdrawal in jails 23 and education in this area would be another avenue of prevention. Finally, floor surfaces could be reviewed to determine if there are any materials that would soften the impact from a fall yet still be adequate from a sanitary perspective to minimize communicable diseases. Developing prevention strategies will thus need multidisciplinary input from medical personnel, material engineers, as well as jail administration and correctional officers.

\section{Conclusion}

In conclusion, bunk bed injuries in jails account for $29 \%$ of all bunk bed injuries in the USA resulting in a visit to an ED for the population 10 years of age and older. A fall from the bed occurred in $72 \%$ and a seizure was 4.5 times more common in jail inmates with a bunk bed injury compared to those not in jails. Possible prevention strategies include railings/ladders to reduce the incidence of fails, changes in flooring surfaces, and seizure education and placing inmates with seizure and/or alcohol related disorders on the bottom bunk. This will require a multidisciplinary approach involving the disciplines of medicine, material engineering, and criminal justice. 


\section{References}

1. Selbst SM, Baker MD. Bunk bed injuries. Am J Dis Child 1990;144:721-723.

2. Macgregor DM. Injuries associated with falls from beds. Inj Prev 2000;6:291-292.

3. Belechri M, Petridou E, Trichopoulos D. Bunk versus conventional beds: a comparative assessment of fall injury risk. J Epidem Comm Health 2002;56:413-417.

4. D'Souza AL, Smith GA, McKenzie LB. Bunk bed-related injuries among children and adolescents treated in emergency departments in the United States, 1990-2005. Pediatrics 2008;121:e1696-e1702.

5. McFaull SR, Frechette M, Skinner R. Emergency department surveillance of injuries associated with bunk beds: the Canadian Hospitals Injury Reporting and Prevention Program (CHIRPP), 1999-2009. Chron Dis Inj Canada 2012;33:38-45.

6. Mack KA, Gilchrist J, Ballesteros MF. Bunk bed-related injuries sustained by young children treated in emergency departments in the United States, 2001-2004, National Electronic Injury Surveillance System - all injury program. Inj Prev 2007;13:137-140.

7. Mayr JM, Seebacher U, Lawrenz K, Pesendorfer P, Berghold A, Baradaran S. Bunk beds - a still underestimated risk for accidents in childhood? Eur J Ped 2000;159:440-443.

8. Eveleth PB, Tanner JM. Worldwide variation in human growth. 2nd ed. Cambridge: University Press, 1990.

9. Annest JL, Mercy JA, Gibson DR, Ryan GW. National estimates of nonfatal firearm-related injuries. Beyond the tip of the iceberg. JAMA 1995;273:1749-1754.

10. Hopkins RS. Consumer product-related injuries in Athens, Ohio, 1980-1985: Assessment of emergency room-based surveillance. Am J Prev Med 1989;5:104-112.

11. Connolly v. County of Suffolk Civil Action No. 04-10835-RGS. Memorandum and order on motion for summary judgement. 533 F.Supp.2d 236; 2008. United States District Court, D.

Massachusetts. February 1, 2008.

http://www.leagle.com/decision/2008769533FSupp2d236_1746/CONNOLLY\%20v.\%20COUNTY\%20 OF\%20SUFFOLK. Accessed April 4, 2017.

12. Sung H-E. Nonfatal violence-related and accident-related injuries among jail inmates in the United States. Prison Journal 2010;90:353-368.

13. Maruschak LM. HIV in prisons and jails, 2002. Washington, DC: Bureau of Justice Statistics US Department of Justice, Office of Justice Programs; 2004.

14. Wilper AP, Woohandler S, Boyd JW, Lasser KE, McCormick D, Bor DH, et al. The health and health care of US prisoners: results of a nationwide survey. Am J Pub Health 2009;99:666-672.

15. Maruschak LM. Medical problems of jail inmates. Washington, DC: Bureau of Justice Statistics 
US Department of Justice, Office of Justice Programs; 2006.

16. Durand E, Watier L, Fix M, Weiss JJ, Chevignard M, Pradat-Diehl P. Prevalence of traumatic brain injury and epilepsy among prisoners in France: results of the Fleury TBI study. Brain Injury 2016;30:363-372.

17. Novick LF, Penna RD, Schwartz MS, Remmlinger E, Loewenstein R. Health status of the New York City prison population. Medical Care 1977;15:205-216.

18. King LN, Young QD. Increased prevalence of seizure disorders among prisoners. JAMA 1978;239:2674-2675.

19. Frost R, Hanzlick R. Deaths in custody. Atlanta City jail and Fulton County jail, 1974-1985. Am J For Med Path 1988;9:207-211.

20. Government Printing Office. Code of Federal Regulations, Title 16, Commercial Practices, Part 1000 to End. Washington, DC January 1, 2017. https://www.gpo.gov/fdsys/pkg/CFR-2017-title16vol2/pdf/CFR-2017-title16-vol2.pdf. Accessed September 5, 2017.

21. Konda S, Reichard AA, Tiesman HM. Occupational injuries among US correctional officers, 1999-2008. J Safety Res 2012;43:181-186.

22. Manasco A, Chang S, Larriviere J, Hamm L, Glass M. Alcohol withdrawal. South Med J 2012;105:607-612.

23. Fiscella K, Pless N, Meldrum S, Fiscella P. Benign neglect or neglected abuse: drug and alcohol withdrawl in U.S. jails. J Law Med Ethics 2004;32:129-136. 


\section{FIGURE LEGENDS}

Figure 1: Body part injured and diagnosis from jail bunk bed injuries.

Figure 2: Age histogram of bunk bed injuries comparing those occurring in or outside of jail. 


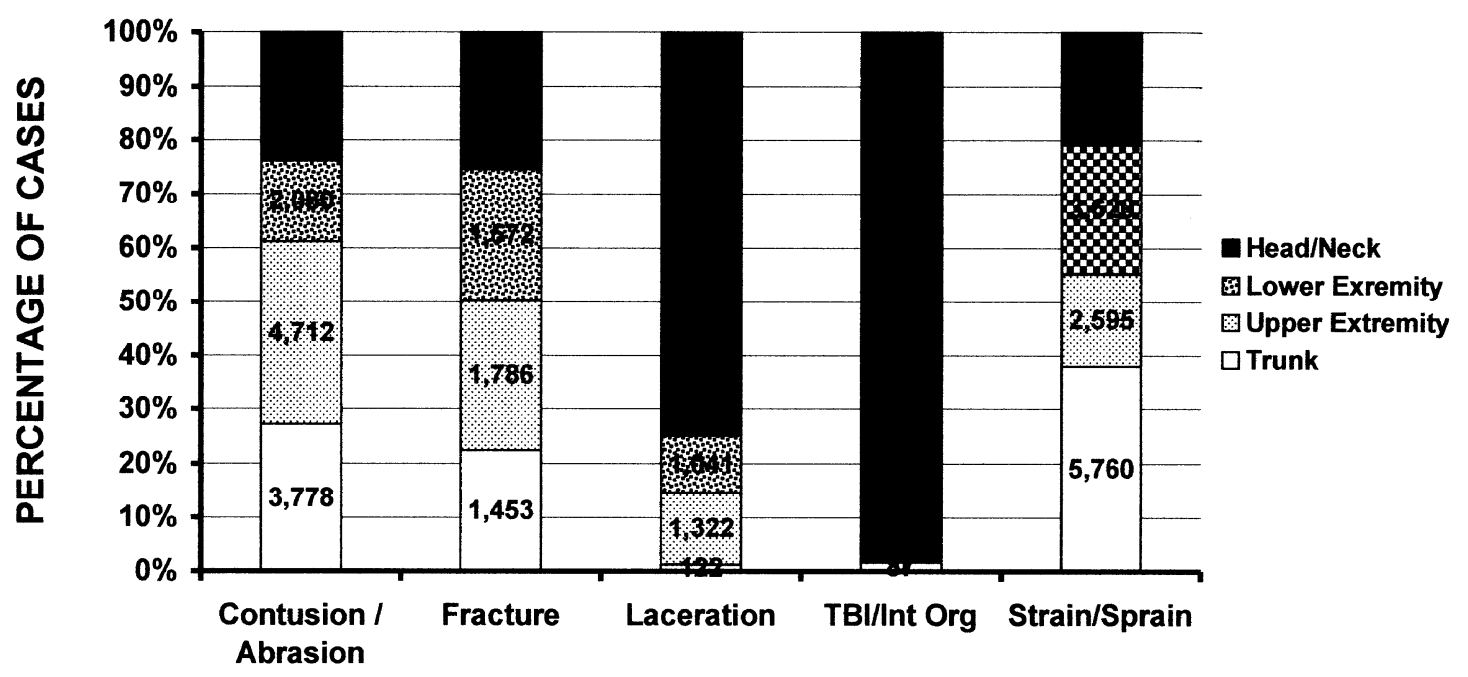

ANATOMIC AREA 


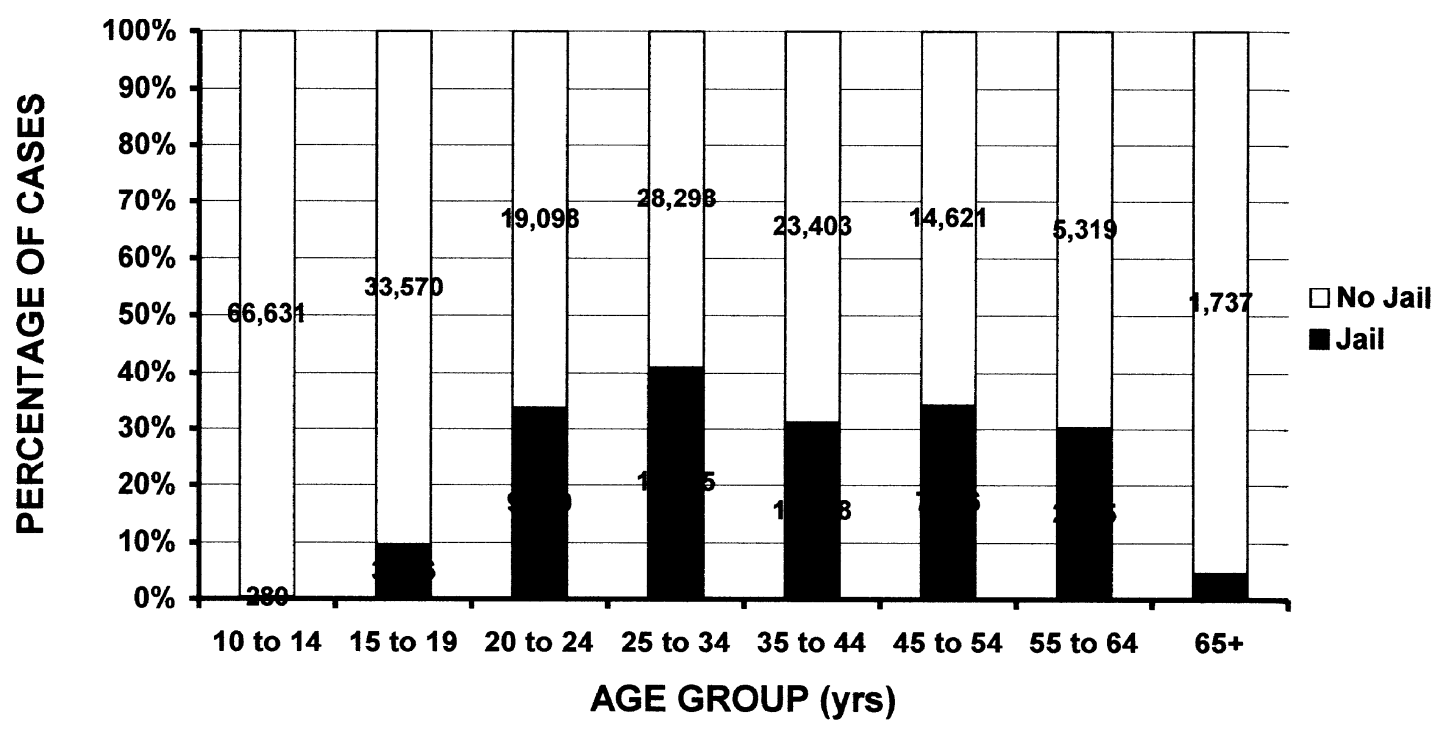


Highlights

- Injuries associated with bunk beds that occur in jail account for $28.9 \%$ of all ED bunk bed injury visits in those over 9 years of age

- A fall off the bunk bed accounted for $71.8 \%$ of the injuries

- Seizure disorder is 4.5 times more common in jail inmates compared to others in those over 9 years of age 
There are no conflicts of interest 